\title{
Overcurrent and Differential Protections for Power Substations Using Three-Winding Transformer
}

\author{
Doan Kim Tuan \\ Electrical Faculty, Thai Nguyen University of Technology, Thai Nguyen, Vietnam
}

DOI: https://doi.org/10.52403/ijrr.20220184

\begin{abstract}
This paper presents a method to determine parameters of overcurrent and differential protections for power substations using threewinding power transformers. Active current threshold and time and working area are shown in this paper to help to calculate and set above relaying protections. An experimental model depicted a relaying system for a power substation using two three-winding power transformers is built to serve education training. It has a complete system structure of relaying protection, including a Arduino Mega 2560 processor, measuring system emulated by variable resistors, real time module and SD card module to record fault events, relays to represent on/off states of circuit breakers. Parameters of relaying protections can be adjusted in the processor to customize the its operation of system and make a visual view about its responses in real working process of power substations. Results received from the model showed the accurate setting method and its meaning that help to verify theory and make clear about relaying protections in education training.
\end{abstract}

Keywords: Overcurrent protection, differential protection for power transformer, relaying protection for power transformer, setting parameters for relaying protection, active current threshold, working time.

\section{INTRODUCTION}

The amount of power transformers in power systems have been higher and higher. Each power substation often has some transformers and they can be operated in parallel/self-contained modes. In the operating process, power transformers must be set many solutions to adapt to different working states, where relaying protection is a compulsory requirement for transmitted transformers having high rated power. It helps to detect unnormal working states and give integrating decisions automatically to trip circuit breakers out if happening any changes higher or lower than limitations [1].

The system of relay protection for power substations can includes many different types depending on rated power of transformers, the complexity and role of the substation in the power system. They can be definite (50) or inverse (51) overcurrent protection; differential protections for transformer (87) and busbar; etc. Above types are main protections for power substations, so they will be make clear in next contents [1], [2].

Differential protection for power transformers uses current signals from current transformers (CT) at all terminal sides of the power transformer to detect faults inside it. Other side, overcurrent protection detects faults at outside of differential area and can be considered as a backup protection for the differential protection. In working process, each protection must be designed to adapt to many requirements, such as: not be acted in states of normal and starting motors; not be active before main protection in total time that is enough to eliminate faults out [1], [2]. So, determining current threshold and trip time for above protections is very difficult and it requires deep knowledge about this problem. Ref [3] concerned with an experimental model to set parameters for 
relaying protection by programming tools and executive device. This is a good way to make a visual view and enhance knowledge for students in process of education training about relaying protection.

This paper focuses on the method to determine parameters of overcurrent and differential protections and applying it into a real power substation on an experimental model. The next section will present the principle of relaying protections for threewinding transformers and method to determine parameters of both overcurrent and differential protections. The third section will represent an application of relaying protections for the $110 \mathrm{kV}$ Gang Thep power substation in Vietnam. The fourth section will show an experimental model to depict two above relaying protection to serve education training. The last section will represent some conclusions and contributions.

\section{Principle of protective relaying and method to determine parameters}

A. Principle of protective relaying for power substations using three-winding transformers

The principle of protective relaying for a three-winding three-phase power transformer is depicted in Fig. 1 [1], [2].

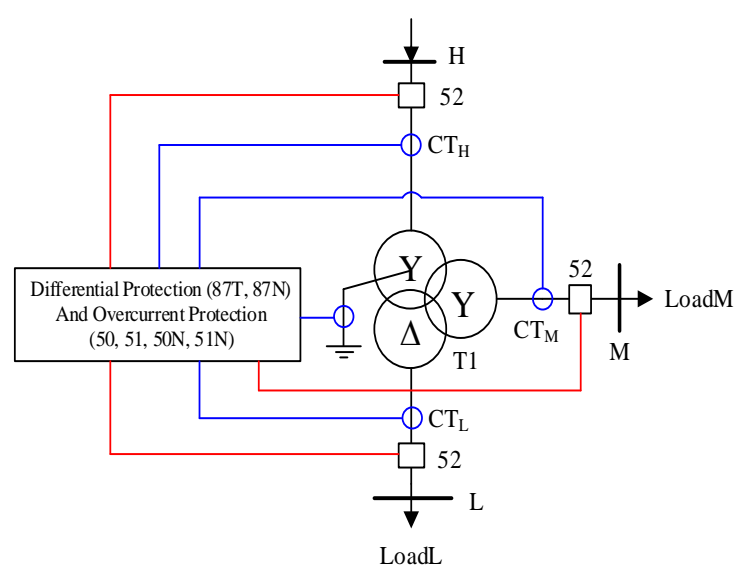

Fig. 1 The principle of protective relaying for three-winding three-phase power transformer

The transformer is connected to power system at high-voltage bus (bus $\mathrm{H}$ ) to supply power for electric load at bus $\mathrm{M}$ and bus L. Symbols for relaying protection are defined by ANSI/IEEE standards.

In Fig. 1, current signals are collected from three sides of the transformer by CTs. Relays use them to calculate and compare to current setting thresholds to trip/not trip circuit breakers (52). Intermediate devices will receive trip signals sent by relays to supply power for trip windings in circuit breakers.

To do this principle, there are many type of relaying device that can be adapt to requirements such as 7UT613, 7SJ600, etc. They often execute the following protections: $87 \mathrm{~T}$ for short-circuiting in windings; $87 \mathrm{~N}$ for short-circuiting in windings and earth; 50 (definite time) and 51 (inverse time) to reserve protection for $87 \mathrm{~T} ; 50 \mathrm{~N}$ and $51 \mathrm{~N}$ to reserve protection for $87 \mathrm{~N}$.

\section{B. Determine parameters of overcurrent protective relaying}

Protection 50 is used to trip the transformer instantaneously (trip time is 0 ) whenever happening short circuit at bus $\mathrm{M}$ or bus L (out of differential area). Pick-up current of protection 50 is defined by (1) [1]:

$$
I_{\text {pick-ip50 }}=k_{\text {reserved }} I_{N \max }
$$

where: $\mathrm{k}_{\text {reserved }}=(1,5 \div 4)$ is reserved factor and $\mathrm{I}_{\mathrm{Nmax}}$ is maximum short circuit current going through $\mathrm{CT}$.

It means that protection 50 will trip circuit breaker instantaneously whenever happening value of fault current higher than I pick-up50.

Protection 51 will trip faulted area in a delayed time. It often uses to detect many types of faults with high ability to selective trip and not tripping to pick-up/inrush current of motor/transformer, etc. Pick-up current of protection 51 is defined by (2) [1]:

$$
I_{\text {pick-up } 51}=k_{\text {reserved }} I_{\text {operating } \max }
$$

where: $k_{\text {reserved }}=(1,5 \div 2)$ is reserved factor and $\mathrm{I}_{\text {operatingmax }}$ is maximum operating current going through CT. 
Doan Kim Tuan. Overcurrent and differential protections for power substations using three-winding transformer.

A specified characteristic of protection 51 is to have variable trip time corresponding to the value of fault current and selected setting curve. Numeric relays often use ANSI/IEC standards as the following formulas in TABLE $I$ and TABLE II [4], [5]:

Table 1: Tripping time corresponding to IEC standard

\begin{tabular}{|l|c|}
\hline Type & Time function \\
\hline Inverse & $\mathrm{t}=\mathrm{TMS} \frac{0,14}{\mathrm{k}^{0,02}-1}$ \\
\hline Very inverse & $\mathrm{t}=\mathrm{TMS} \frac{13,5}{\mathrm{k}^{1}-1}$ \\
\hline Extremely inverse & $\mathrm{t}=\mathrm{TMS} \frac{80}{\mathrm{k}^{2}-1}$ \\
\hline Long time inverse & $\mathrm{t}=\mathrm{TMS} \frac{120}{\mathrm{k}^{1}-1}$ \\
\hline
\end{tabular}

where: TMS is Time Multiplier Setting; $\mathrm{k}=\mathrm{I} / \mathrm{I}_{\text {pick-up }}$; I is short circuit current

Table 2: Tripping time corresponding to ANSI standard
\begin{tabular}{|l|l|}
\hline Type & Time function \\
\hline Inverse & $\mathrm{t}=\mathrm{TMS}\left(\frac{8,9341}{\mathrm{k}^{2,0938}-1}+0,17966\right)$ \\
\hline Short inverse & $\mathrm{t}=\mathrm{TMS}\left(\frac{0,2663}{\mathrm{k}^{1,2969}-1}+0,03393\right)$ \\
\hline Long inverse & $\mathrm{t}=\mathrm{TMS}\left(\frac{5,6143}{\mathrm{k}-1}+2,18592\right)$ \\
\hline Moderately inverse & $\mathrm{t}=\mathrm{TMS}\left(\frac{0,0103}{\mathrm{k}^{0,02}-1}+0,0228\right)$ \\
\hline Very inverse & $\mathrm{t}=\mathrm{TMS}\left(\frac{3,922}{\mathrm{k}^{2}-1}+0,0982\right)$ \\
\hline Extremely inverse & $\mathrm{t}=\mathrm{TMS}\left(\frac{5,64}{\mathrm{k}^{2}-1}+0,02434\right)$ \\
\hline Definite inverse & $\mathrm{t}=\mathrm{TMS}\left(\frac{0,4797}{\mathrm{k}^{1,5625}-1}+0,21359\right)$ \\
\hline I2T & $\mathrm{t}=\frac{\mathrm{TMS} \times 50,7+10,14}{\mathrm{k}^{2}}$ \\
\hline
\end{tabular}

Corresponding to each type, there are many different curves depicted in Fig. 2 [4]. [5].

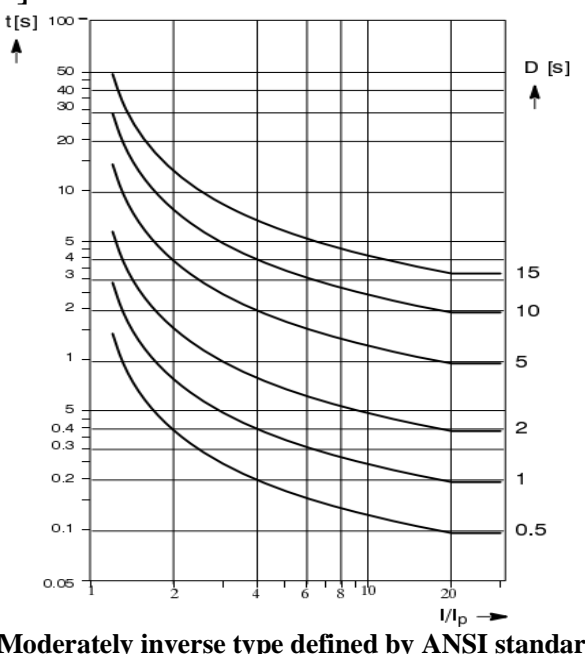

a. Moderately inverse type defined by ANSI standard

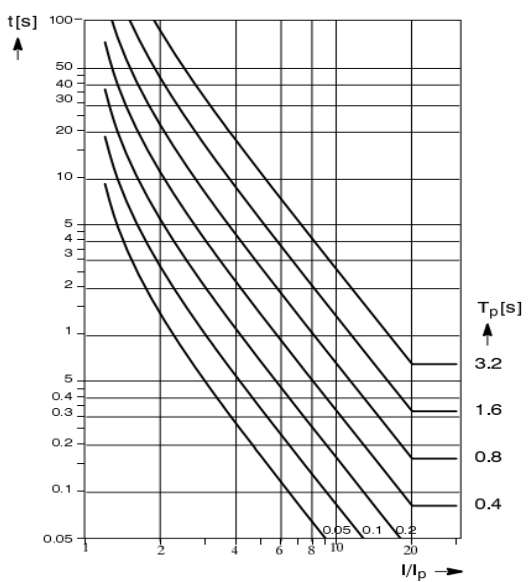

b. Extremely inverse type defined by IEC standard Fig. 2 Curves of ANSI/IEC standard

\section{c. Determine parameters of differential protective relaying}

Operating area of protection $87 \mathrm{~T}$ for the transformer is represented in Fig. 3.

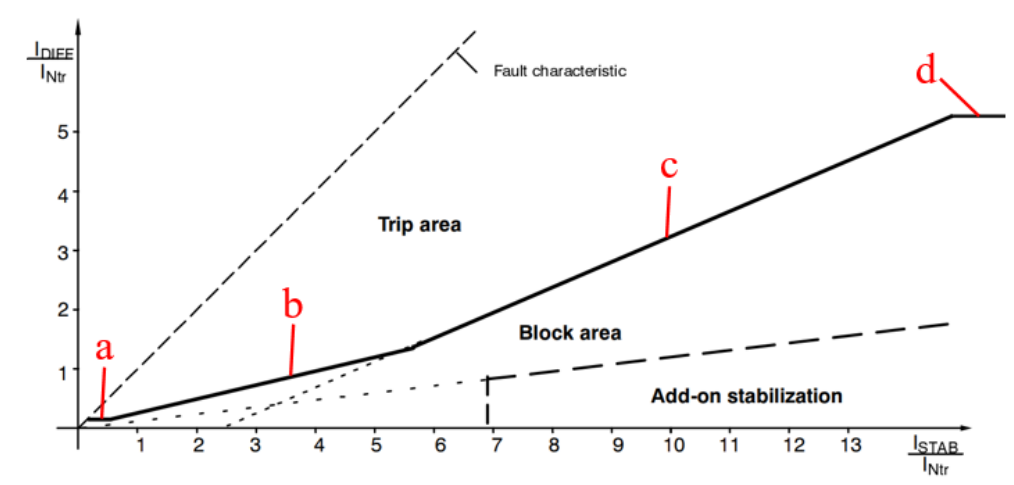

Fig. 3. Operating area of protection 87T for the transformer 
Doan Kim Tuan. Overcurrent and differential protections for power substations using three-winding transformer.

where: $\quad I_{D I F F}=\left|I_{1}+I_{2}+I_{3}\right|$
$I_{\text {STAB }}=\left|I_{1}\right|+\left|I_{2}\right|+\left|I_{3}\right|$

In normal operating mode, operating point is always in the block area due to

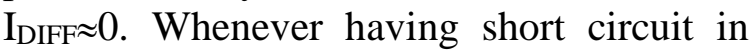
the power area between CTs, current through CTs will change their directions and create high IDIFF. Corresponding to this mode, fault characteristic is established and operating point can be dropped to trip area in Fig. 3.

Parameters of each segment in Fig. 3 can be defined as following:

\section{Segment a:}

This segment is used to specify for low threshold corresponding to nonbalanced current in normal operating mode. It can be defined by (3):

$I_{\text {low-threshold }}=k_{\text {reserved }} I_{\text {non-balanced }}$

where:

$\mathrm{k}_{\text {reserved }}=(1,2 \div 1,3)$ is reserved factor,

$I_{\text {non-balanced }}=\varepsilon_{\Sigma} I_{\text {ratedT }}$ is non-balanced current,

$\varepsilon_{\Sigma}$ is total error, depending on stable inrush current of the power transformer, error of self-relays, error of on-load regulator of the transformer, maximum error of CTs when having maximum short circuit current out of differential area (short-circuit at bus $\mathrm{M}$ or bus L).

transformer.

$I_{\text {rated }}$ is rated power of the

\section{Segment b:}

Segment $b$ is defined by a straight line going through the origin point and slope (SL) calculating from angle $\alpha_{1}$. This SL helps to ensure the reliability in case of having non-balanced current that caused by the error of CT and the change of the onload regulator. It is often from 0.1 to 0.5 .

The minimum value of segment $b$ can be defined by (4):

$$
S L_{\min b}=\frac{\varepsilon_{\Sigma}}{k\left(200-\varepsilon_{\Sigma}\right)} \times 100 \%
$$

where $\mathrm{k}$ is locked factor.

$\mathrm{k}$ selected smaller than 1 to have $S L_{\min \mathrm{b}} \geq \varepsilon_{\Sigma}$.

\section{Segment c:}

Although CTs are often chosen to avoid saturation in the transformer in case of maximum current out of protective area, the transient process of CTs aren't still considered deeply. Moreover, $\mathrm{X} / \mathrm{R}$ ratio from CTs to short-circuiting point, the effect of DC components in short circuit current and inductance at secondary of CTs are not evaluated. In almost studied about differential protection with transient mode of CTs, we have $100(\mathrm{U} \neg \mathrm{S}-\mathrm{Uk}) / \mathrm{Uk}=10 \%$ corresponding to the transient state of CTs type $\mathrm{C}$ and $\varepsilon_{\Sigma \max }=50 \%$. So, the minimum SL of c segment can be defined by (5):

$S L_{\min c}=\frac{\varepsilon_{\Sigma \max }}{k\left(200-\varepsilon_{\Sigma}\right)} \times 100 \%$

\section{Segment d:}

Value of high threshold in segment $d$ is defined by (6):

$\mathrm{I}_{>}=\frac{1}{\mathrm{U}_{\mathrm{N} \min } \%} \times 100 \%$

where: $U_{N \min } \%=\min \{\mathrm{UNC}-\mathrm{T}$; UNC-H $\}$ for three-winding transformer.

\section{Add-on stabilization area:}

This area is designed to avoid wrong activation in case of the saturation of CTs corresponding to short-circuiting out of differential area. The start-up point this area Iadd on $\mathrm{STAB}=7$. and its slope $=1 / 2$ the slope of segment $b$.

For 87T, the pick-up current is chosen by 0.3 IratedT.

III. An apllication and calculation for relaying protection in $110 \mathrm{kv}$ Gang Thep power subation, Thai nguyen, vietnam

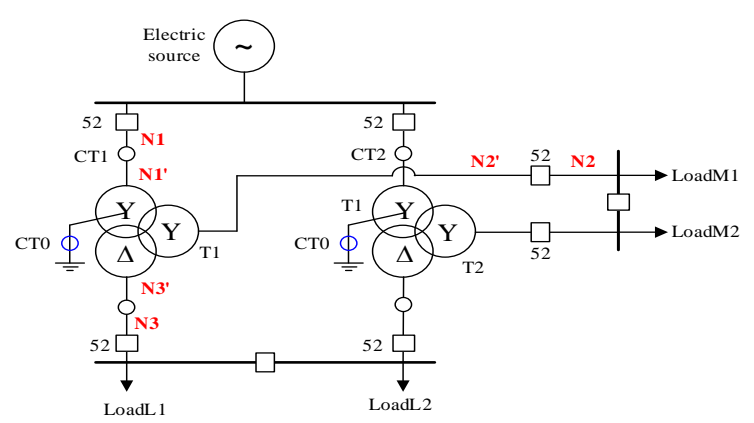

Fig. 4. One-line diagram for $110 \mathrm{kV}$ Gang Thep power substion, Thai Nguyen, Vietnam 
Doan Kim Tuan. Overcurrent and differential protections for power substations using three-winding transformer.

The one-line diagram with assumed six-point short circuits of $110 \mathrm{kV}$ Gang Thep power substation, Thai Nguyen, Vietnam is depicted in Fig. 4.

Considered relaying protections are overcurrent protection (using 7SJ600 relay) and differential protection (using 7UT613 relay). Parameters of transformers are given in TABLE III. Currents going through CTs are calculated with results as depicted in TABLE IV. Parameters of CTs are shown in TABLE V.

Table 3. Parameters of transformers

\begin{tabular}{|c|c|c|c|c|c|}
\hline \multirow{2}{*}{$\begin{array}{l}S_{\text {ratedT }} \\
\text { (MVA) }\end{array}$} & \multicolumn{3}{|c|}{$\mathbf{U}_{\text {rated, }}, \mathbf{k V}$} & \multirow{2}{*}{$\begin{array}{l}\Delta \mathbf{P}_{\mathrm{N}}(\mathrm{kW}) \\
\mathrm{C}-\mathrm{H}\end{array}$} & \multirow{2}{*}{$\mathbf{i}_{0}, \%$} \\
\hline & $\mathrm{C}$ & $\mathbf{T}$ & $\mathbf{H}$ & & \\
\hline 63 & 110 & 38.5 & 6.3 & 270 & 0.6 \\
\hline \multirow{2}{*}{$\Delta \mathrm{P}_{0}(\mathrm{~kW})$} & \multirow{2}{*}{\multicolumn{2}{|c|}{ Voltage regulator }} & \multicolumn{3}{|c|}{$\mathrm{U}_{\mathrm{N}}, \%$} \\
\hline & & & C-T & C-H & $\mathrm{T}-\mathrm{H}$ \\
\hline 50.4 & \multicolumn{2}{|c|}{ $\pm 1.78 \times 9$} & 12.5 & 17 & 6.5 \\
\hline
\end{tabular}

Table 4. Currents going through CTs

\begin{tabular}{|c|c|c|c|c|c|c|c|}
\hline \multirow[t]{2}{*}{ Operating mode } & \multirow{2}{*}{\multicolumn{2}{|c|}{ Short circuit point }} & \multicolumn{2}{|c|}{ CT1 (kA) } & \multirow{2}{*}{$\begin{array}{l}\text { CT2 }(\mathrm{kA}) \\
\text { N2 and N2' }\end{array}$} & \multirow{2}{*}{\begin{tabular}{|l|} 
CT3 $(\mathrm{kA})$ \\
N3 and N3'
\end{tabular}} & \multirow{2}{*}{$\begin{array}{l}\text { CT0 (kA) } \\
-\end{array}$} \\
\hline & & & N1 & N1' & & & \\
\hline \multirow[t]{6}{*}{ Parallel } & \multicolumn{2}{|l|}{$\mathrm{N}^{(3)}$} & - & 38.8 & 14.74 & 67.32 & - \\
\hline & \multicolumn{2}{|l|}{$\mathrm{N}^{(2)}$} & - & 33.6 & 12.76 & 58.3 & - \\
\hline & \multirow[t]{2}{*}{$\mathrm{N}^{(1,1)}$} & $\mathrm{I}_{\mathrm{N}(-0)}^{1,1}$ & 23.13 & - & - & - & - \\
\hline & & $\mathrm{I}_{0}$ & - & 7.69 & - & - & 1.9 \\
\hline & \multirow[t]{2}{*}{$\mathrm{N}^{(1)}$} & $\mathrm{I}_{\mathrm{N}(-0)}^{1}$ & 29 & - & - & - & - \\
\hline & & $\mathrm{I}_{0}$ & - & 9.66 & - & - & 4.77 \\
\hline \multirow[t]{2}{*}{ Operating mode } & & & \multicolumn{2}{|c|}{ CT1 (kA) } & CT2 (kA) & CT3 (kA) & CT0 (kA) \\
\hline & \multicolumn{2}{|c|}{ Short circuit point } & N1 & N1' & $\mathrm{N} 2$ and N2' & N3 and N3' & - \\
\hline \multirow[t]{6}{*}{ Self-contained } & \multicolumn{2}{|l|}{$\mathrm{N}^{(3)}$} & - & 38.8 & 7.89 & 35.41 & - \\
\hline & \multicolumn{2}{|l|}{$\mathrm{N}^{(2)}$} & - & 33.6 & 6.84 & 30.67 & - \\
\hline & \multirow[t]{2}{*}{$\mathrm{N}^{(1,1)}$} & $\mathrm{I}_{\mathrm{N}(-0)}^{1,1}$ & 23.13 & - & - & - & - \\
\hline & & $\mathrm{I}_{0}$ & - & 7.69 & - & - & 1.9 \\
\hline & \multirow[t]{2}{*}{$\mathrm{N}^{(1)}$} & $\mathrm{I}_{\mathrm{N}(-0)}^{1}$ & 29 & - & - & - & - \\
\hline & & $\mathrm{I}_{0}$ & - & 9.66 & - & - & 4.77 \\
\hline
\end{tabular}

Table 5. Parameters of CTs corresponding to 7UT613 and 7SJ600

\begin{tabular}{|l|l|l|l|l|}
\hline \multirow{2}{*}{ Parameters } & $\mathbf{1 1 0} \mathbf{k V}$ & $\mathbf{3 5} \mathbf{k V}$ & $\mathbf{6 ~ k V}$ \\
\cline { 2 - 4 } & $\mathbf{7 U T 6 1 3}$ & $\mathbf{7 S J 6 0 0}$ & & \\
\hline $\begin{array}{l}\text { Current transformer } \\
\text { ratio }\end{array}$ & $2000 / 5$ & $500 / 5$ & $2000 / 5$ & $4000 / 5$ \\
\hline CT type & C200 & C200 & C200 & C400 \\
\hline
\end{tabular}

Using methods to determine protective parameters in section II and parameters in TABLE III, TABLE IV and
TABLE V, we have parameters of overcurrent protection (for ANSI inverse type) as given in Table VI and characteristic of differential protection as given in Fig. 5 .

Table 6. Parameters of protective relaying

\begin{tabular}{|l|l|l|l|l|l|l|l|}
\hline \multicolumn{1}{|l|}{ Pick-up current } & \multicolumn{5}{|l|}{ Pick-up time } \\
\hline $\mathbf{5 0}$ & $\mathbf{5 1}$ & $\mathbf{5 1 N}$ & $\mathbf{8 7 N}$ & $\mathbf{5 0}$ & $\mathbf{5 1}$ & $\mathbf{8 7}$ & $\mathbf{5 1 N}$ \\
\hline $61,9 \mathrm{~A}$ & $10 \mathrm{~A}$ & $1.4 \mathrm{~A}$ & $1.4 \mathrm{~A}$ & $0.01 \mathrm{~s}$ & $0.36 \mathrm{~s}$ & $0.07 \mathrm{~s}$ & $0.45 \mathrm{~s}$ \\
\hline
\end{tabular}

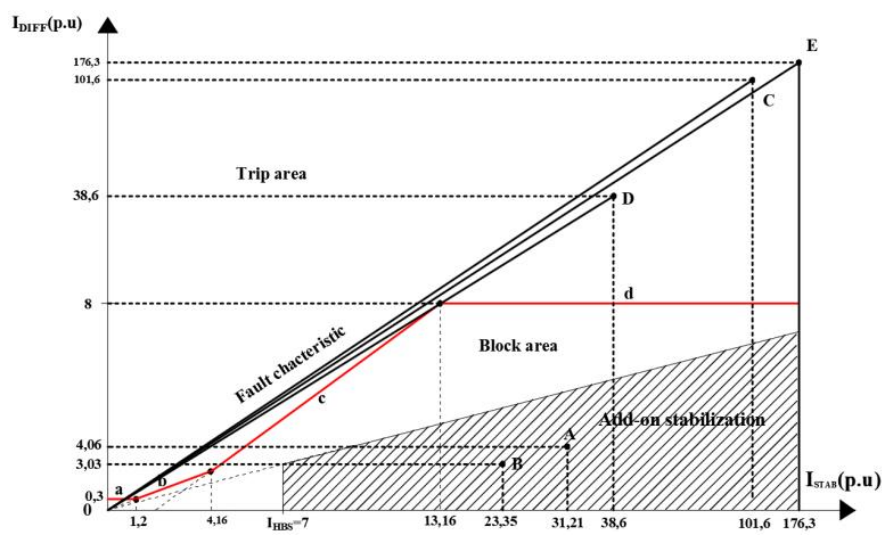

Fig. 5 Differential characteristic for transformers in $110 \mathrm{kV}$ Gang Thep power substation, Thai Nguyen, Vietnam

IV. EXPERIMENTAL MODEL AND RESULTS

\section{A. Experimental model}

The diagram of model connection is shown in Fig. 6. 
Doan Kim Tuan. Overcurrent and differential protections for power substations using three-winding transformer.

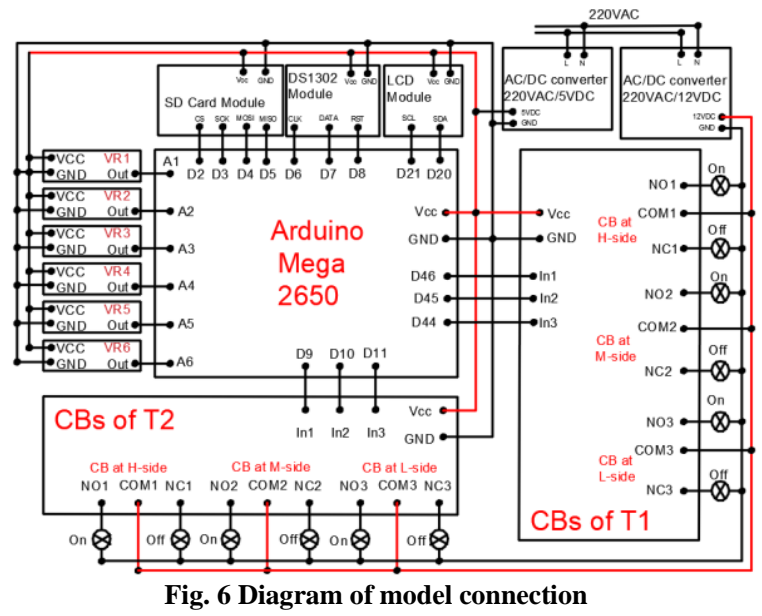

Fig. 6 Diagram of model connection
This system includes an Arduino Mega 2560 board as a center processor, a SD card module to record fault events, a DS1302 module to provide real time information, a LCD module to display information, variable resistors to suppose fault currents, relays to represent on/off states.

All main devices in this model is depicted in Fig. 7. Human-Machine Interface (HMI) between them and computer is shown in Fig. 7.

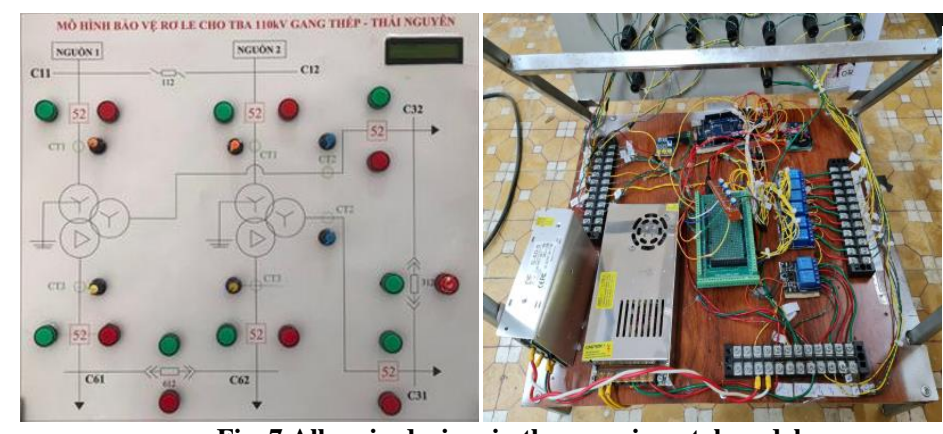

Fig. 7 All main devices in the experimental model

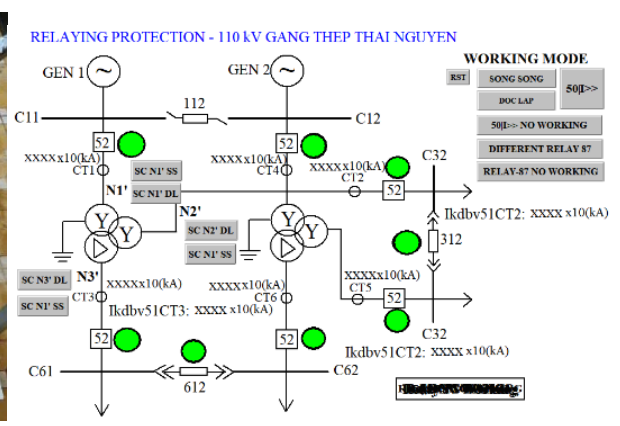

Fig. 8 HMI
Control software is designed to suppose parallel and self-contained operating modes of transformers. Moreover, protection 50, 51 and $87 \mathrm{~T}$ can be set by buttons Short circuit points are also supposed by selecting buttons as SC N1', SC N2', SC N3'. Values of fault currents and operating states of circuit breakers (green LED for off state and red LED for on state) are displayed in both HMI and LCD.

\section{B. Experimental results in parallel mode}

To select parallel mode, the operator presses "SONG SONG" button in HMI. If all transformers works normally, all circuit breakers will be closed (red LED is on).

\section{- Check the response of protection 50}

Supposing an event with a short circuit point at $\mathrm{M}$-side transformers, press button 'SC N2' SS". Turning up the variable resistor at $\mathrm{M}$-side of $\mathrm{T} 1$ transformer to calculated threshold, protection 50 will be acted instantaneously. At this time, circuit breakers at all sides of T1 transformer and two circuit breakers linking two segments of $\mathrm{M}$ and $\mathrm{L}$ buses are also tripped instantaneously (LED changed from red indicators to green indicators). Operating results of protection 50 before and after short-circuiting are represented in Fig. 9.

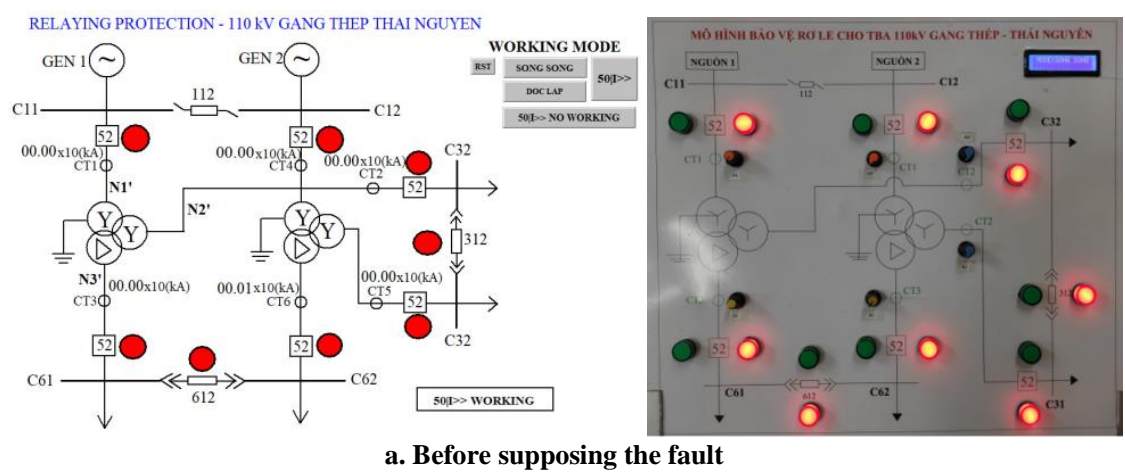


Doan Kim Tuan. Overcurrent and differential protections for power substations using three-winding transformer.

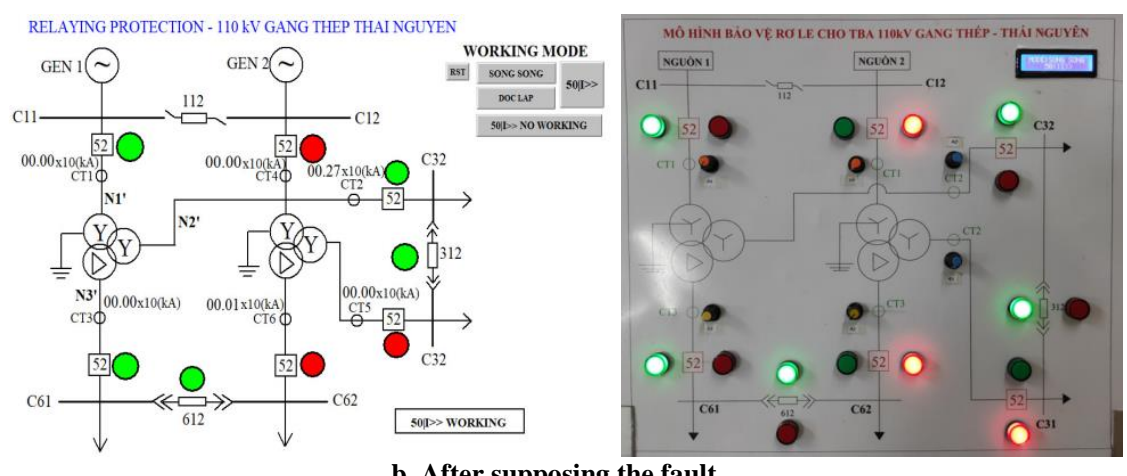

b. After supposing the fault

Fig. 9 Operating results of protection 50 in parallel mode

\section{- Check the response of protection 87T}

Supposing an event with a short circuit point at N1', press button 'SC N2' SS". Turning up the variable resistor at three sides of $\mathrm{T} 1$ transformer to calculated threshold, protection $87 \mathrm{~T}$ will be acted instantaneously. At this time, circuit breakers at all sides of $\mathrm{T} 1$ transformer are also tripped after setting time (LED changed from red indicators to green indicators). while two circuit breaker linking two segments of $\mathrm{M}$ and $\mathrm{L}$ buses still works normally (red indicators are still held). Operating results of protection $87 \mathrm{~T}$ before and after short-circuiting are represented in Fig. 10.
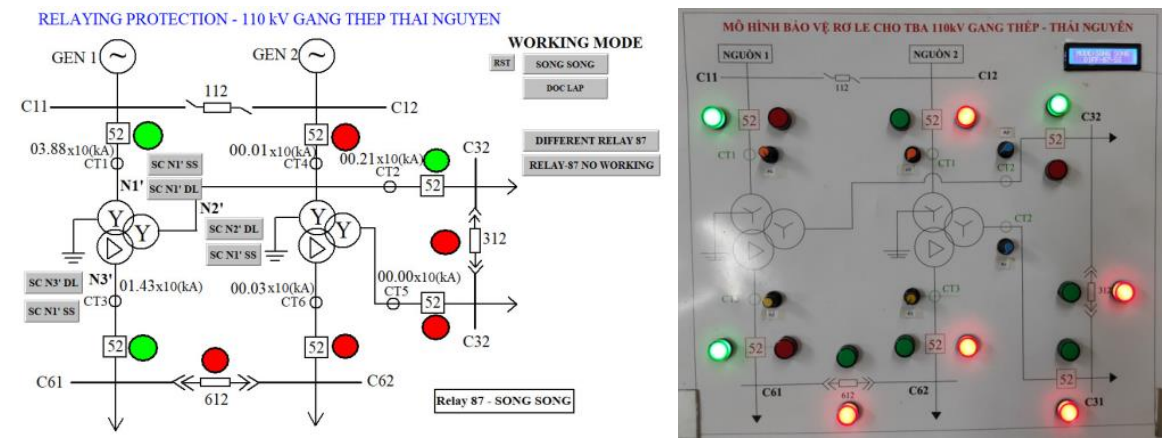

Fig. 10 Operating results of protection 87T in parallel mode

- Check the response of protection 51

Protection 51 is designed to reserve for protection 50 and 87 , so it must be press "50|I $>>$ No Working" and "RELAY-87 No Working" buttons to check the response of protection 51. Supposing an event with a short circuit point at M-side transformers, press button "SC N3 SS". Turning up the variable resistor at L-side of $\mathrm{T} 1$ transformer to calculated threshold, protection 51 will be acted after calculated time. After sending control signals, circuit breakers at all sides of $\mathrm{T} 1$ transformer and two circuit breakers linking two segments of $\mathrm{M}$ and $\mathrm{L}$ buses are also tripped (LED changed from red indicators to green indicators). Operating results of protection 50 before and after short-circuiting are represented in Fig. 11.

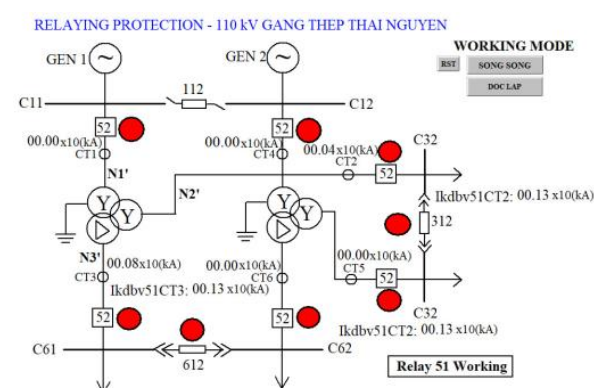

a. Without being acted in normal working mode
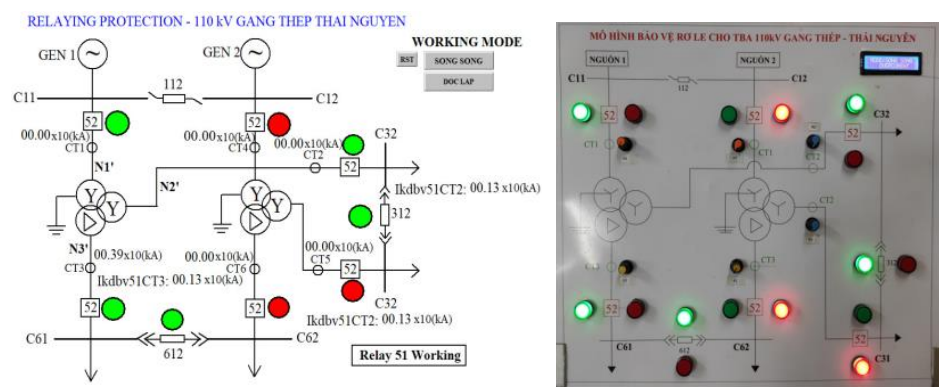

b. Tripped $\mathrm{T} 1$ transformer by protection 51

Fig. 11 Operating results of protection 51 in parallel mode 
Doan Kim Tuan. Overcurrent and differential protections for power substations using three-winding transformer.

\section{c. Experimental results in self-contained operating mode}

To work in self-contained operating mode, press button "DOC LAP". In this mode, two circuit breakers linking two segments of $\mathrm{M}$ and $\mathrm{L}$ buses are also opened
(LED changed from red indicators to green indicators) while all circuit breakers are closed. Operating results of protection 50 before and after short-circuiting are represented in Fig. 12.

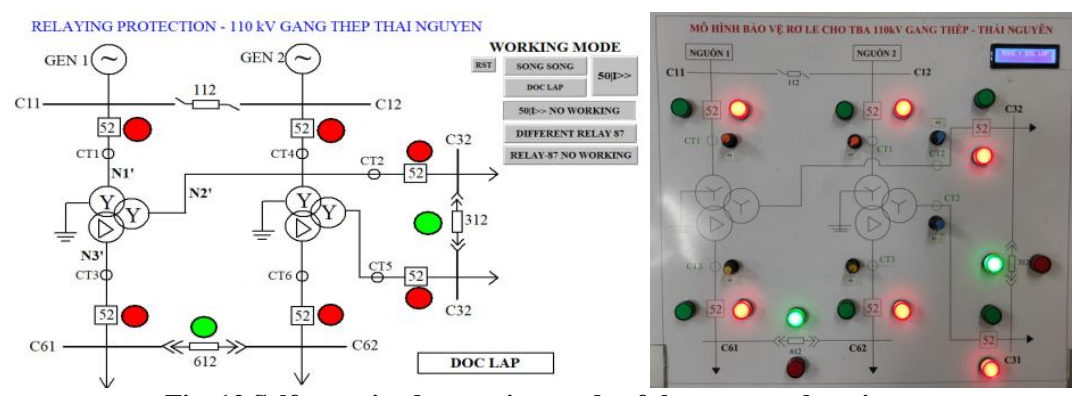

Fig. 12 Self-contained operating mode of the power substation

\section{- Check the response of protection 50}

Supposing an event with a short circuit point at L-side T2 transformers, turning up the variable resistor at L-side of T2 transformer to calculated threshold, protection 50 will be acted instantaneously. At this time, circuit breakers at all sides of
T2 transformer are also tripped instantaneously (LED changed from red indicators to green indicators and two circuit breakers linking two segments of $\mathrm{M}$ and $\mathrm{L}$ buses were tripped before). Operating results of protection 50 before and after short-circuiting are represented in Fig. 13.

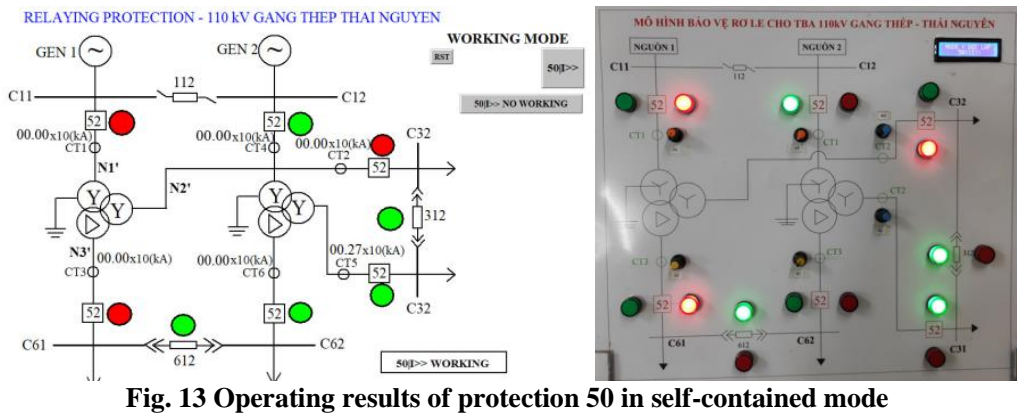

\section{- Check the response of protection 87T}
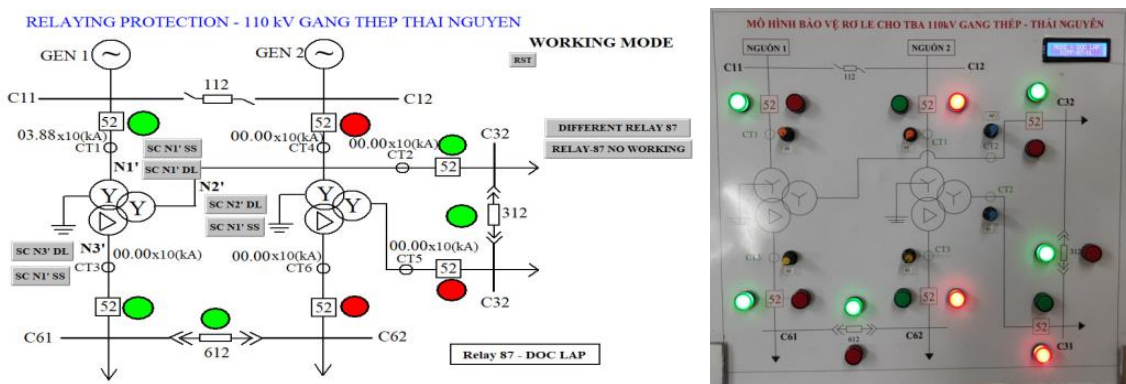

Fig. 14 Check the response of protection $87 \mathrm{~T}$

Supposing an event with a short circuit point at N2', press button 'SC N2' $\mathrm{DL}$ ". Turning up the variable resistor at $\mathrm{L}$ side of $\mathrm{T} 1$ transformer to calculated threshold (currents at $\mathrm{H}$ and $\mathrm{M}$ sides are zero), protection $87 \mathrm{~T}$ will be acted instantaneously. At this time, circuit breakers at all sides of $\mathrm{T} 1$ transformer are tripped after setting time (LED changed from red indicators to green indicators and 
Doan Kim Tuan. Overcurrent and differential protections for power substations using three-winding transformer.

two circuit breakers linking two segments of $M$ and $L$ buses were tripped before). Operating results of protection $87 \mathrm{~T}$ before and after short-circuiting are represented in Fig. 14.

\section{- Check the response of protection 51}

Supposing an event with a short circuit point at M-side transformers, turn up the variable resistor at $\mathrm{M}$-side of $\mathrm{T} 1$ transformer to calculated threshold, protection 51 will be acted after calculated time. After sending control signals, circuit breakers at all sides of $\mathrm{T} 1$ transformer are also tripped (LED changed from red indicators to green indicators and two circuit breakers linking two segments of $\mathrm{M}$ and $\mathrm{L}$ buses). Operating results of protection 51 before and after short-circuiting are represented in Fig. 15.

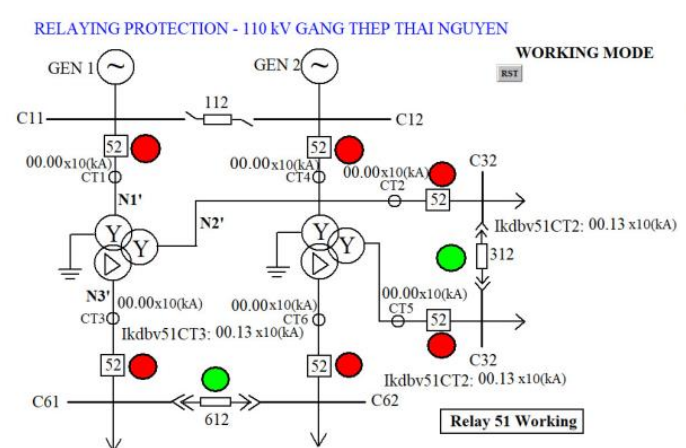

a. Without being acted in normal working mode
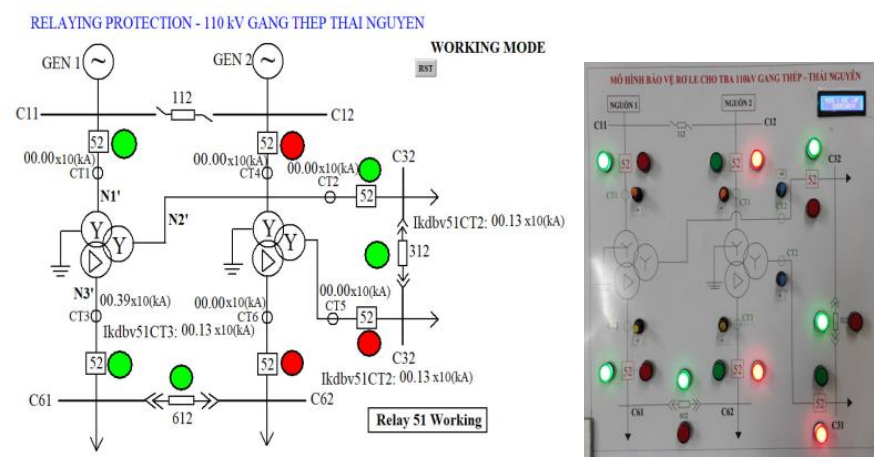

b. Tripped $\mathrm{T} 1$ transformer by protection 51

Fig. 15 Operating results of protection 51 in self-contained mode

All faults were recorded and can be exported to a text file as Fig. 16. The record includes the fault location, type of fault and value of fault current.

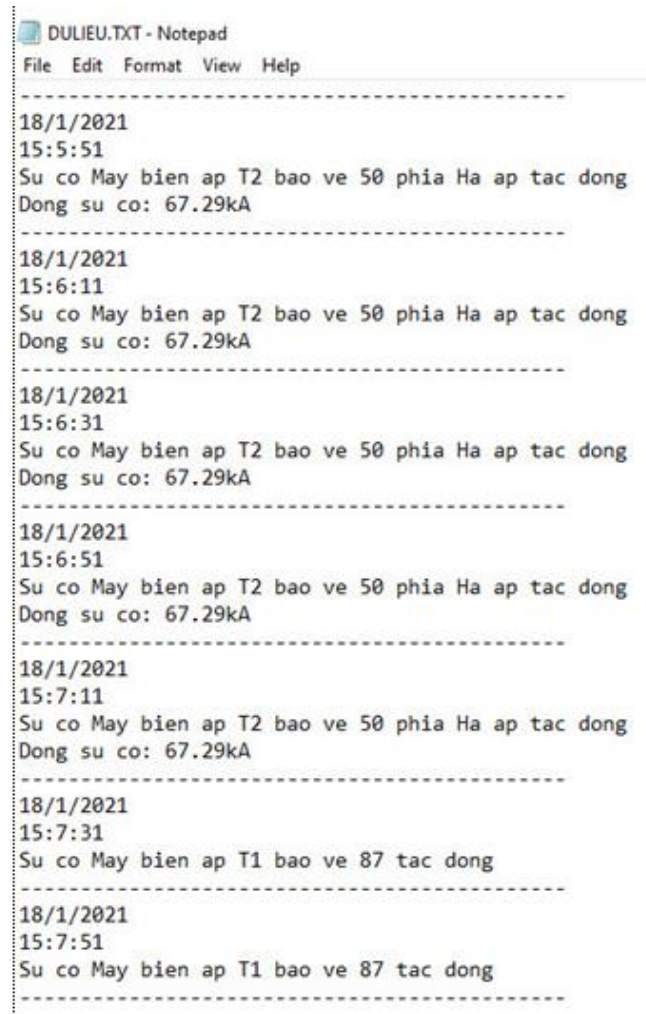

Fig. 16 Record data about faults
Experimental results showed that the model helped to depict normal and fault states, including the activation of relaying system. States of circuit breakers and fault currents were displayed very detailed in HMI, LCD and LED signals that helped operators view all responses of the system in the process of supposing. Record data about operating states (time, fault currents) was saved to have all evaluations about faults.

\section{CONCLUSIONS}

This paper established a method to determine parameters of protection 50,51 and 87 for three-winding three-phase transformers. They include pick-up time and current corresponding to ANSI/IEC standards. Moreover, an experimental model was proposed to served education training with two transformers. It is considered as a virtual model to set and simulate the operation of relaying system and circuit breakers using a microprocessor, real time module, SD module and relays. All calculations are applied for $110 \mathrm{kV}$ Thai Nguyen power substation, Vietnam with an 
Doan Kim Tuan. Overcurrent and differential protections for power substations using three-winding transformer.

experimental model to have total view about whole system.

The experimental model was set with parameters in parallel and selfcontained operating modes of transformers. Two circuit breakers linking two segments of $\mathrm{M}$ and $\mathrm{L}$ buses were closed in parallel mode and opened self-contained mode. Short circuit currents going through CTs was calculated for each operating state to set pick-up current and time. All received results showed that all devices in the model were responded correctly corresponding to the setting about state and parameters. Currently operating parameters and states of circuit breakers were displayed in HMI, LCD and LED signals. They can help operators know about operating conditions of whole system.

The contributions of this paper can help students have total view about the operations of three main relaying protection in power substations. Users can set all parameters by themselves and suppose the operation of the substation before applying to a real substation. Studies about CTs and the contents of the model can be continued to develop with other relaying protection such as $87 \mathrm{~N}, 50 \mathrm{~N}, 51 \mathrm{~N}$, Buchholz relay, etc. Moreover, model can become more intelligent it is ability to selecting curve or type protection to enhance the protective capability.

Acknowledgement: None

\section{Conflict of Interest: None}

\section{Source of Funding: None}

\section{REFERENCES}

1. Tanley H. Horowitz, Arun G. Phadke (2014), "Power System Relaying", John Wiley and Sons Publisher, SBN 978-1-11866200-7.

2. Harjit Singh Kainth, Gagandeep Sharma (2014), "A New Method for Differential Protection in Power Transformer", IOSR Journal of Electrical and Electronics Engineering (IOSR-JEEE) e-ISSN: 22781676,p-ISSN: 2320-3331, Volume 9, Issue 2.

3. Anh V Nguyen, Lien B Nguyen, and Anh Hoang (2020), " A Numerical Relay Implementation for Overcurrent Protection Based on ARM Cortex - M4 Microprocessor", IOP Conf. Series: Materials Science and Engineering 752.

4. Instruction Manual (2001), "Numerical Differential Protection Relay for Transformers, Generators, Motors, and Branch Points 7UT51", Siemens

5. Instruction Manual (1995), "Numerical Overcurrent Time Protection and Thermal Overload Relay with Auto-Reclosure Option SIPROTEC 7SJ600", Siemens

How to cite this article: Doan Kim Tuan. Overcurrent and differential protections for power substations using three-winding transformer. International Journal of Research and Review. 2022; 9(1): 728-737. DOI: https:// doi.org/10.52403/ijrr.20220184 